\title{
The joint probability distribution of runoff and sediment and its change characteristics with multi-time scales
}

\author{
Jinping Zhang ${ }^{*}$, Zhihong Ding ${ }^{2}$, Jinjun You ${ }^{3}$ \\ ${ }^{1}$ Institute of Water Resources and Environment, Zhengzhou University, High-tech District, No. 100 Science Road, Zhengzhou City, \\ 450001, Henan Province, China. \\ ${ }^{2}$ Haihe River Water Conservancy Commission, Tianjin, 300072, China. \\ ${ }^{3}$ State Key Laboratory of Hydrologic Cycle Simulation and Regulation, China Institute of Water Resources \& Hydropower Research, \\ Beijing, 100038, China. \\ * Corresponding author. Tel.: +86-371-60119629. E-mail: jinping2000_zh@163.com
}

\begin{abstract}
River runoff and sediment transport are two related random hydrologic variables. The traditional statistical analysis method usually requires those two variables to be linearly correlated, and also have an identical marginal distribution. Therefore, it is difficult to know exactly the characteristics of the runoff and sediment in reality. For this reason, copulas are applied to construct the joint probability distribution of runoff and sediment in this article. The risk of synchronous-asynchronous encounter probability of annual rich-poor runoff and sediment is also studied. At last, the characteristics of annual runoff and sediment with multi-time scales in its joint probability distribution space are simulated by empirical mode decomposition method. The results show that the copula function can simulate the joint probability distribution of runoff and sediment of Huaxia hydrological station in Weihe River well, and that such joint probability distribution has very complex change characteristics at time scales.
\end{abstract}

Keywords: Runoff; Sediment; Joint probability distribution; Copula; Empirical mode decomposition method.

\section{INTRODUCTION}

For the different meteorological factors and underlying surface conditions, runoff and sediment transport are not independent of each other. Some attempts have been made to study the correlations of the random hydrologic variables in the field of rainfall (i.e., rainfall density, depth, and duration), flood (i.e., flood peak, volume, and duration) and drought (i.e., drought severity, magnitude, and duration), etc. For example, Correia (1987) studied the joint probability distribution of flood peak and volume using bivariate normal distribution. Goel et al. (1998) and Yue (2000) achieved this condition by preliminary data transformation through Box-Cox's formulas to represent the joint probability distribution of peak rainfall intensity and depth. As early as 1985, Hashino (1985) proposed the Freund (1961) bivariate exponential distribution to discuss the joint probability distribution of rainfall intensity and maximum storm surge. Singh and Singh (1991) described the joint probability distribution of rainfall intensity and depth with this mathematic method by using empirical frequency analysis. Han et al. (2007) and Liu and Chen (2009) investigated the risk of synchronousasynchronous encounter probability of annual rich-poor precipitation in the East and Middle Routes of South-to-North Water Transfer Project. Yue (2001), Yue and Rasmussen (2002), and Yue et al. (1999) applied the Gumbel's (1960, 1967) distribution for flood and rainfall frequency analysis. Yue and Wang (2004) constructed the joint risk assessment model to study the relationships between inflow runoff and rainfall of Nangang reservoir in the Hutuohe River Basin. Zhou et al. (2005) verified Gumbel logistic distributions for annual maximum wind speed and effective wave height.

However, the above mentioned works were based on certain assumptions, e.g. that all univariates have the same marginal distributions, and the correlations between variables must be linear. In practice, most of the random hydrologic variables cannot meet those assumptions easily. Therefore, copulas which are based on nonlinear relationships among variables and do not require many assumptions have become prevalent in hydrologic research. Copula function can decompose the joint distribution function into univariable marginal distribution functions and a link function. The flexibility offered by copula for joint probability distribution construction is evident from the relevant studies on rainfall frequency analysis (Balistrocchi and Bacchi, 2011; Gyasi-Agyei, 2012; Gyasi-Agyei and Melching, 2012; Salvatore and Francesco, 2006), flood frequency analysis (Chowdhary et al., 2011; Renard and Lang, 2007; Salarpour et al., 2013; Xiao et al., 2008; Xu et al., 2008; Zhang and Singh, 2007), drought frequency analysis (Kao and Govindaraju, 2010; Ma et al., 2013; Yan et al., 2007), and also the risk analysis of synchronous-asynchronous encounter probability for annual rich-poor rainfall or runoff (Ganguli and Reddy, 2013; Lian et al., 2013; Xiong et al., 2005). Although the prior works have been done by other researchers, there are still some undiscovered aspects of the copula applications in hydrology, especially on the joint probability distribution of runoff and sediment transport in sandy rivers.

In the study of hydrologic variables with a long time series, wavelet analysis is an effective method (Compagnucci et al., 2000; Gaucherel, 2002; Labat et al., 2004; Wang and Meng, 2007). But limited by Fourier transform, the signal must be stable inside the wavelet window. Although wavelet transform can get higher resolution in the frequency domain and time domain, there are still some restrictions in wavelet transform, which results in many false harmonics. Moreover, the selection of different wavelet base functions has significant impact on wavelet analysis. In 1998, Huang et al. (1998) proposed a new signal analysis method - empirical mode decomposition, and later made some improvements (Huang et al., 1999). Empirical mode decomposition method can extract fluctuations or trends of a signal step by step at different scales (frequency) simultaneously, which produces data series with different characteristics-intrinsic mode function. Hilbert-Huang 
transform, applying Hilbert transform on intrinsic mode function, is very suitable for nonlinear and non-stationary time series. Although it is similar to wavelet spectrum, Hilbert spectrum provides clearer and more detailed partial features. The key of Hilbert-Huang transform is to get spectra with higher resolution in time domain and frequency domain. At present, empirical mode decomposition method has been successfully applied in turbulence, earthquake research, atmospheric science and ecology, environment, economy and other nonlinear areas, but very rarely in hydrology.

The aims of this paper are to (1) get marginal distribution of runoff and sediment with frequency distribution curve of P-IIItype; (2) construct the joint probability distribution model of runoff and sediment with copulas; (3) analyze the risk of synchronous-asynchronous encounter probability of annual rich-poor runoff and sediment; (4) present the characteristics of runoff and sediment with multi-time scale in the joint probability distribution space by empirical mode decomposition method.

\section{COPULAS}

\section{Sklar theorem}

Sklar theorem is the basis of copula theory. Suppose there are two continuous random variables denoted as $X$ and $Y$, let $F_{X}(x)$ and $F_{Y}(y)$ be the marginal distribution functions of $X$ and $Y$, and $F(x, y)$ be the joint distribution function. If $F_{X}(x)$ and $F_{Y}(y)$ are continuous, a uniquely determined copula function $C_{\theta}(u, v)$ exists as b (Nelsen, 1999):

$$
F(x, y)=C_{\theta}\left(F_{X}(x), F_{Y}(y)\right), \quad \forall x, y
$$

where, $C_{\theta}(u, v)$ is called copula function, $\theta$ is parameter to be determined.

\section{The properties of copula function}

A bivariate copula function is defined as a mapping $\mathrm{C}:[0,1]^{2} \rightarrow[0,1]$ with the following properties:

(a) $\forall u, v \in[0,1]$

$$
\begin{aligned}
& C(u, 0)=0 ; C(0, v)=0 ; \\
& C(u, 1)=u ; C(1, v)=v ;
\end{aligned}
$$

(b) $\forall u_{1}, u_{2}, v_{1}, v_{2} \in[0,1], u_{1} \leq u_{2}, v_{1} \leq v_{2}$,

$$
\begin{aligned}
& C\left(u_{2}, v_{2}\right)-C\left(u_{2}, v_{1}\right)-C\left(u_{1}, v_{2}\right)+C\left(u_{1}, v_{1}\right) \geq 0 \\
& \text { (c) } \forall u, v \in[0,1]^{2}, \\
& \max (u+v-1,0) \leq C(u, v) \leq \min (u, v)
\end{aligned}
$$

\section{The correlation of copula function}

The most popular three types of copula functions in hydrology are shown as Table 1 (Cherubini et al., 2004; Grimaldi et al., 2005), which belong to the Archimedean copula family. $\tau$ is Kendall's correlation coefficient. It describes the nonlinear correlation of variables and can be estimated using the equation:

$\tau=\frac{1}{C_{n}^{2}} \sum_{i<j} \operatorname{sign}\left[\left(x_{i}-x_{j}\right)\left(y_{i}-y_{j}\right)\right]$

where, $\operatorname{sign}\left[\left(x_{i}-x_{j}\right)\left(y_{i}-y_{j}\right)\right]=\left\{\begin{array}{cc}1 & \left(x_{i}-x_{j}\right)\left(y_{i}-y_{j}\right)>0 \\ 0 & \left(x_{i}-x_{j}\right)\left(y_{i}-y_{j}\right)=0 \\ -1\left(x_{i}-x_{j}\right)\left(y_{i}-y_{j}\right)<0\end{array}\right.$

\section{Identification and goodness-of-fit evaluation of copula function}

Using the Kolmogorov-Smirnov test, the appropriate copula is identified. The identified statistic is given by:

$$
D=\max _{1 \leq k \leq n}\left\{\left|C_{k}-\frac{m_{k}}{n}\right|,\left|C_{k}-\frac{m_{k}-1}{n}\right|\right\}
$$

where, $C_{k}$ is the value of observed $\left(x_{k}, y_{k}\right)$ of the copula function, $m_{k}$ is the number of observed $\left(x_{k}, y_{k}\right)$ satisfying with $x \leq x_{k}$ and $y \leq y_{k}$. The goodness-of-fit of copula function is evaluated by the minimum deviation square) with the following expression:

\begin{tabular}{|c|c|c|c|}
\hline $\begin{array}{l}\text { Archimedean } \\
\text { copula }\end{array}$ & $C_{\theta}(u, v)$ & $\theta$ 's range & Relation between $\tau$ and $\theta$ \\
\hline Clayton & $\left(u^{-\theta}+v^{-\theta}-1\right)^{-1 / \theta}$ & $\theta>0$ & $\tau=\frac{\theta}{\theta+2}$ \\
\hline Frank & $-\frac{1}{\theta} \ln \left[1+\frac{\left(e^{-\theta u}-1\right)\left(e^{-\theta v}-1\right)}{e^{-\theta}-1}\right.$ & $\theta \in R$ & $\tau=1-\frac{4}{\theta}\left[-\frac{1}{\theta} \int_{\theta}^{0} \frac{t}{\exp (t)-1} d t-1\right.$ \\
\hline Gumbel-Hougaard & $\exp \left[-\left((-\ln u)^{\theta}+(-\ln v)^{\theta}\right)^{1 / \theta}\right]$ & $\theta \geq 1$ & $\tau=1-\frac{1}{\theta}$ \\
\hline
\end{tabular}

$$
O L S=\sqrt{\frac{1}{n} \sum_{i=1}^{n}\left(P_{i}-P_{e i}\right)^{2}}
$$

where, $P_{i}$ is the calculated frequency of the joint probability distribution, $P_{e i}$ is the empirical frequency of the joint probability distribution, $O L S$ is the minimum deviation square.

Table 1. Three Archimedean copula families in the field of hydrology research. 


\section{EMPIRICAL MODE DECOMPOSITION METHOD}

Intrinsic mode function proposed by Huang must satisfy two following conditions: (1) In the whole data range, the number of local extremes and the number of zero-crossings must be equal or at most have a difference of 1; (2) At any point, the mean value of the upper envelope formed by all local maxima and the lower envelope formed by all local minima is zero.

The key step of empirical mode decomposition method is to extract intrinsic mode function from the given time series $x(t)$.

First, the upper envelope and the lower envelope are constructed by identified local maxima points and local minima points with a cubic spline interpolation application. Then, the mean value of the two envelopes is calculated as $m_{1}$, and a new time series removing lower frequency is achieved by:

$$
h_{1}(t)=x(t)-m_{1}
$$

usually, $h_{1}(t)$ is not an expected intrinsic mode function, so we need to repeat this shifting process $k$ times until the obtained mean envelopes are zero. At this moment, the final time series can be shown as:

$h_{1 k}=h_{1(k-1)}-m_{1 k}$

where, $h_{1 k}$ is the series of shifting process $k$ times, $h_{1(k-1)}$ is the series of shifting process $k-1$ times. Intrinsic mode function is evaluated to stop the shifting process by the criterion of standard deviation value between $0.2 \sim 0.3$. The criterion of standard deviation is defined as:

$S D=\sum_{k=1}^{T} \frac{\left|h_{1(k-1)}(t)-h_{1 k}(t)\right|^{2}}{h_{1(k-1)}(t)^{2}}$ where, $S D$ is the criterion of standard deviation, $T$ is the length of the time series. When $h_{1 k}$ arrives at the stopping criterion of standard deviation, we have the first intrinsic mode function component $c_{1}=h_{1 k}$ from the data $x(t)$ which represents the highest frequency component of the original time series. The residue $r_{1}=x(t)-c_{1}$ will be decomposed further until $r_{n}$ becomes a monotonic function or at most has one local extreme point. Thus, we get intrinsic mode function modes with one residue $r_{n}$. The original series $x(t)$ is then rewritten as:

$x(t)=\sum_{i=1}^{n} c_{i}+r_{n}$

Now, each intrinsic mode function component represents a data series of a characteristic scale (or frequency). In fact, the empirical mode decomposition method decomposes original data series into various fluctuations owning different features, and then superimposes them. Each intrinsic mode function may be either linear or non-linear, and all decomposed intrinsic mode function components have the actual corresponding physical significances

\section{APPLICATION \\ Data series}

The Weihe River is the largest tributary of the Yellow River in China. About $55 \%$ of runoff comes from the area above the Xianyang hydrologic station on the mainstream of the Weihe River, while $80 \%$ of sediment is from the Jinghe River, a tributary of the Weihe River. Huaxian hydrological station, located $73 \mathrm{~km}$ from the river mouth at Goujiabao village (Hua County, Shaanxi Province), is the main control station of the lower reaches of the Weihe River. Catchment area is $106,500 \mathrm{~km}^{2}$ (shown as in Fig.1).

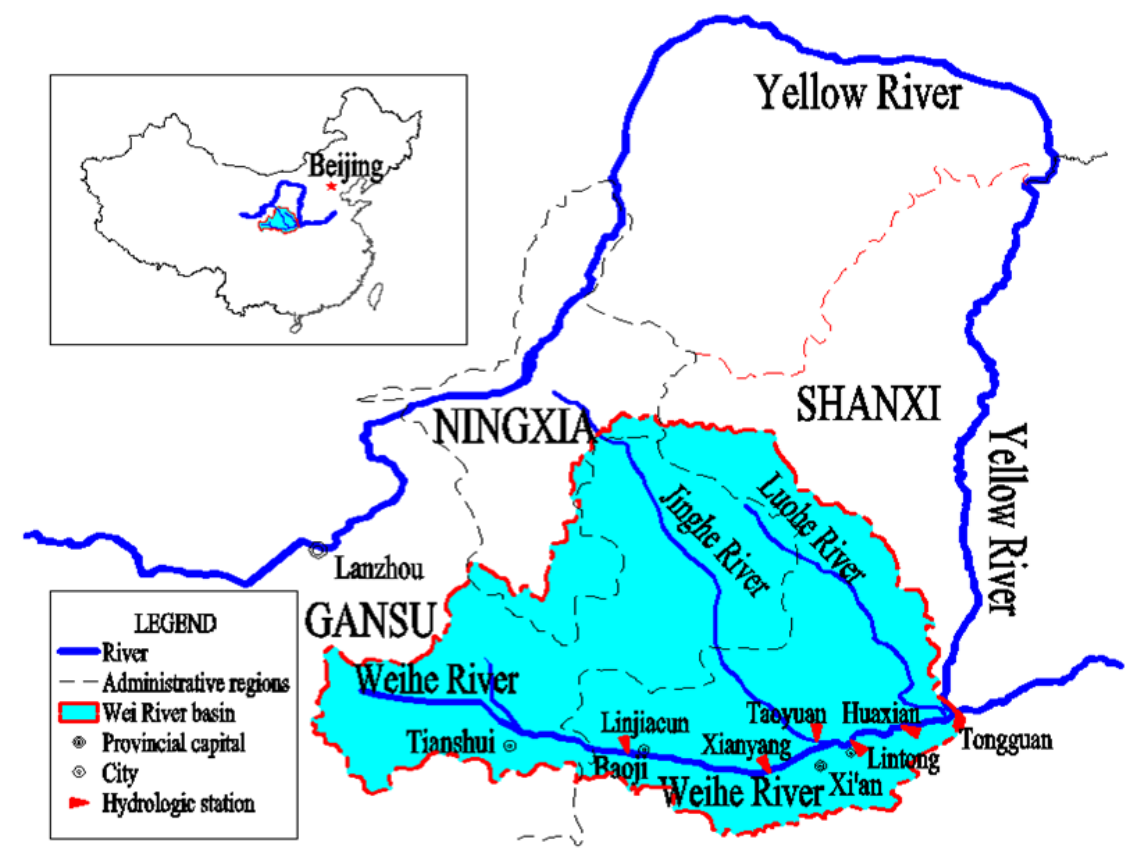

Fig. 1. The location of the study site in China. 
The observed runoff and sediment data series of Huaxian hydrological station used in this article are from 1935 to 2008 (shown as in Fig. 2). These data series are all obtained from the hydrology bureau of the Yellow River Conservancy Commission. The hydrology bureau of the Yellow River Conservancy Commission is the hydrologic authority in the Yellow River Basin, so the monitoring, collection and disposal of the hydrological and meteorological information in the whole Yellow River Basin is one of its main activities. Meanwhile, because the hydrology bureau of the Yellow River Conservancy Commission is a pilot unit for the establishment of scientific data sharing platform in the field of hydrology and water resources, the hydrological database structure and the data have passed the national acceptance. Thus, the quality of the observed runoff and sediment data series of Huaxian hydrological station used in this paper is well guaranteed.

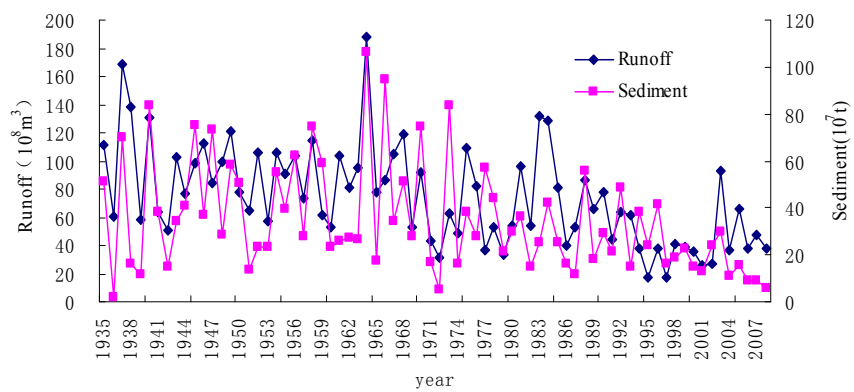

Fig. 2. The annual runoff and sediment data series at Huaxian hydrological station.

\section{P-III-type frequency distribution curve of runoff and sediment}

Hydrologic analysis in China generally assumes the hydrologic variable subjects to P-III-type distribution. In this paper, the statistical parameters of runoff frequency distribution shown in Fig. 3 and sediment frequency distribution shown in Fig. 4 are obtained by optimal fitting method. We can see that the mean value $\bar{x}$, coefficient of variation $C_{\mathrm{v}}$ and the skewness coefficient $C_{\mathrm{s}}$ in runoff series are $74.7 \times 10^{8} \mathrm{~m}^{3} / \mathrm{s}, 0.48$ and 0.79 separately, while in the sediment series they are $3.47 \times 10^{8} \mathrm{~m}^{3} / \mathrm{s}$, 0.68 and 1.51 .

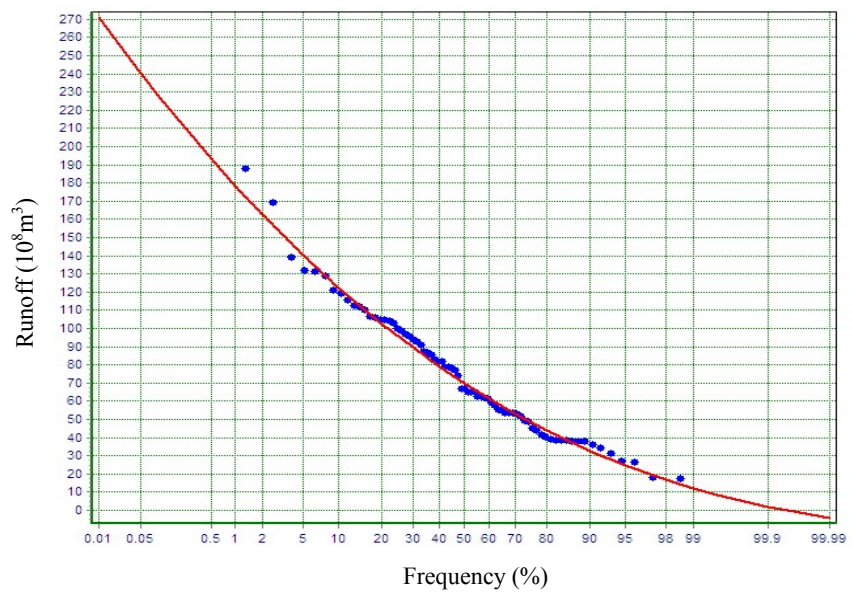

Fig. 3. Frequency distribution curve of annual runoff.

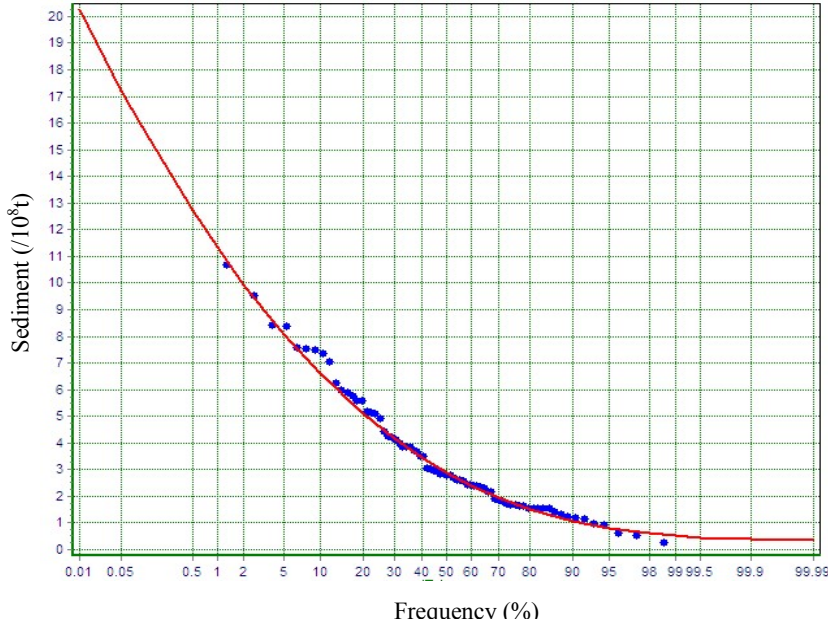

Fig. 4. Frequency distribution curve of annual sediment.

Joint probability distribution of runoff and sediment based on copulas

According to the above mentioned formulas, Kendall's correlation coefficient $\tau$, parameter $\theta$ of copula function, identified statistic $D$ and the minimum deviation square $O L S$ can be achieved (shown as in Table 2).

Table 2. Calculation and evaluation of copula functions.

\begin{tabular}{|c|c|c|c|c|}
\hline \multirow{2}{*}{$\begin{array}{c}\text { Kendall's } \\
\tau\end{array}$} & \multirow{2}{*}{$\begin{array}{c}\text { Parameter } \\
\text { or index }\end{array}$} & \multicolumn{3}{|c|}{ Copula functions } \\
\hline & & Clayton & Frank & $\begin{array}{l}\text { Gumbel- } \\
\text { Hougaard }\end{array}$ \\
\hline \multirow{3}{*}{0.5969} & $\theta$ & 1.3467 & 4.1942 & 1.6734 \\
\hline & $D$ & 0.0636 & 0.0577 & 0.0701 \\
\hline & $O L S$ & 0.02445 & 0.02246 & 0.02829 \\
\hline
\end{tabular}

Taking the significance level $\alpha=0.05$, when $n=74$, the corresponding fractile value of $K-S$ test is 0.15549 , it must not be less than identified statistic $D$ of undetermined copula functions. From Table 2, we know that these three copula functions are all checked by Kolmogorov-Smirnov test with a small difference of their minimum deviation square values. For its minimum value of deviation square, Frank copula function is selected to describe the joint probability distribution of the runoff and sediment in the lower reaches of the Weihe River. The selected Frank copula function is expressed as:

$$
F(x, y)=-\frac{1}{4.1942} \ln \left[1+\frac{\left(e^{-4.1942 x}-1\right)\left(e^{-4.1942 y}-1\right)}{e^{-4.1942}-1}\right]
$$

where, $F(x)$ and $F(y)$ are cumulative distribution functions of runoff and sediment separately.

The goodness-of-fit evaluation of selected Frank copula function is shown in Fig. 5. The correlation coefficient of Frank copula-based calculation probability distribution and empirical probability distribution attains to above 0.99 , and all points fall near the $45^{\circ}$ diagonal. It reveals that Frank copula is reasonable. 


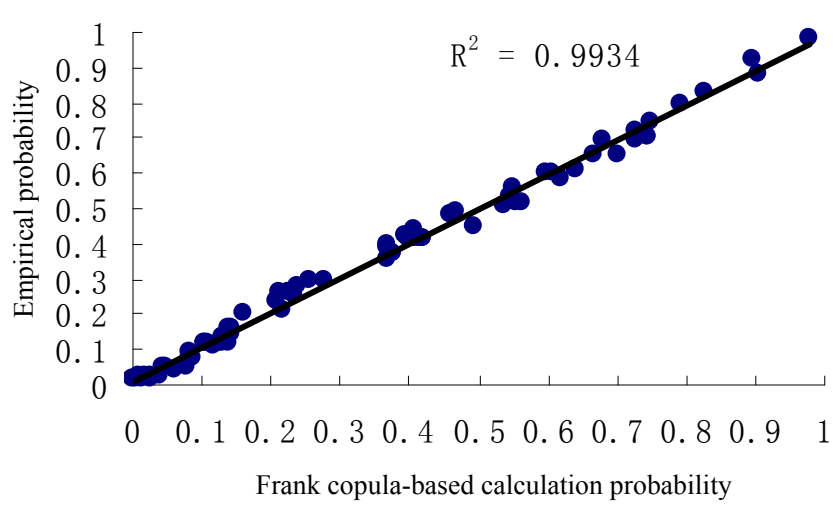

Fig. 5. The comparison of Frank copula-based calculation probability with empirical probability.

The frequency analysis of synchronous-asynchronous encounter situation of annual runoff and sediment

According to the frequency of $p f=37.5 \%$ and $p k=62.5 \%$, the rich or poor situation of runoff and sediment are classified. The synchronous-asynchronous encounter situation of annual rich-poor runoff and sediment are expressed as follows:

Rich-rich encounter frequency:

$p_{1}=P\left(X \geq x_{p f}, Y \geq y_{p f}\right)$;

Rich-normal encounter frequency:

$p_{2}=P\left(X \geq x_{p f}, y_{p k}<Y<y_{p f}\right)$;

Rich-poor encounter frequency:

$p_{3}=P\left(X \geq x_{p f}, Y \leq y_{p k}\right)$;

Normal-rich encounter frequency:

$p_{4}=P\left(x_{p k}<X<x_{p f}, Y \geq y_{p f}\right)$;

Normal-normal encounter frequency:

$p_{5}=P\left(x_{p k}<X<x_{p f}, y_{p k}<Y<y_{p f}\right)$;

Normal-poor encounter frequency:

$p_{6}=P\left(x_{p k}<X<x_{p f}, Y \leq y_{p k}\right)$;

Poor-rich encounter frequency:

$p_{7}=P\left(X \leq x_{p k}, Y \geq y_{p f}\right)$;

Poor-normal encounter frequency:

$p_{8}=P\left(X \leq x_{p k}, y_{p k}<Y<y_{p f}\right)$;

Poor-poor encounter frequency:

$p_{9}=P\left(X \leq x_{p k}, Y \leq y_{p k}\right)$.

The frequency analysis of synchronous-asynchronous encounter situation of annual rich-poor runoff and sediment is displayed in Table 3.

It can be seen that: (1) Synchronous encounter frequency of annual rich runoff and rich sediment is $24.21 \%$, which is equal to synchronous encounter frequency of annual poor runoff and poor sediment. Synchronous encounter frequency of annual normal runoff and normal sediment is the minimum value of $8.04 \%$; (2) Asynchronous encounter frequency of rich (or poor) runoff and poor (or rich) sediment is only $4.81 \%$ while others are all $8.48 \%$; (3) The total synchronous encounter frequency is $56.46 \%$.It is larger than that of asynchronous encounter frequency with the value of $43.54 \%$.
The return period and risk analysis of synchronousasynchronous encounter probability of annual runoff and sediment

Let $F(x)$ and $F(y)$ be the marginal cumulative distribution function of runoff $(x)$ and sediment $(y)$, and $F(x, y)$ be their joint distribution function. The synchronous-asynchronous encounter risk of annual runoff and sediment is denoted as the return period $T$. Here, two kinds of return periods are considered:

$$
\left\{\begin{aligned}
T_{x, y} & =\frac{1}{1-F(x, y)} \\
T^{*}{ }_{x, y} & =\frac{1}{1-F(x)-F(y)+F(x, y)}
\end{aligned}\right.
$$

where, $T_{x, y}$ is joint return period, indicating that the exceeded risk of any design variable; $T^{*} x, y$ is simultaneous return period, indicating the exceeded risk of all design variables.

With the constructed joint probability distribution, the encounter return periods of runoff and sediment are shown in Fig. 6 and Fig. 7.

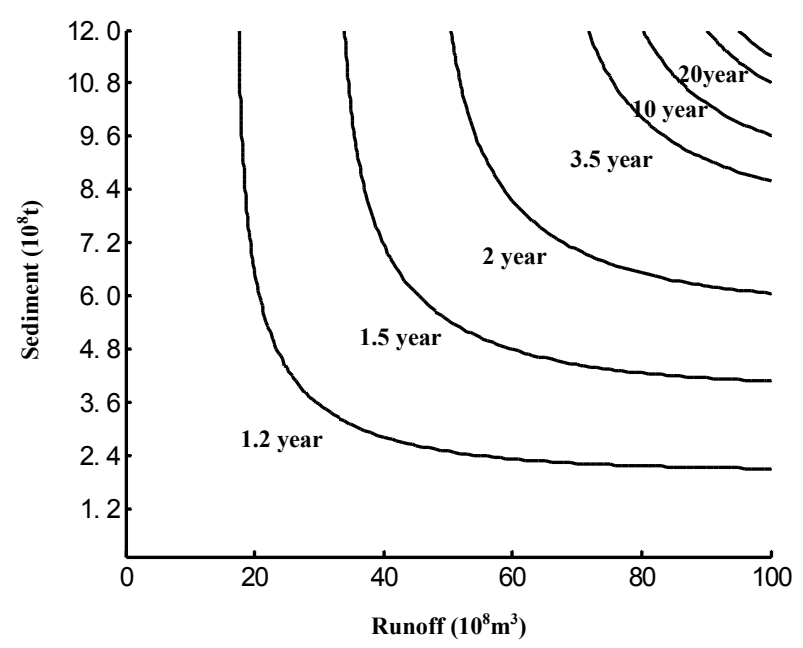

Fig. 6. Isopleths map for runoff and sediment of the joint return periods.

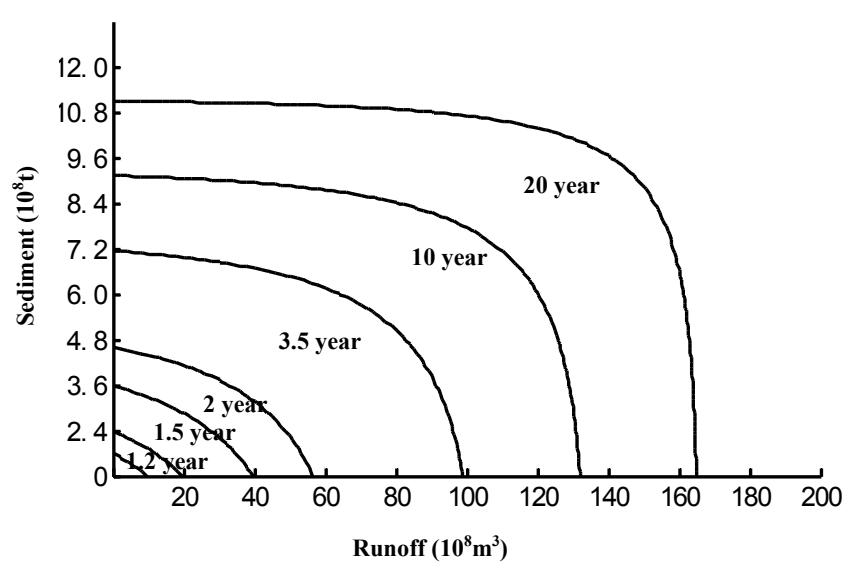

Fig. 7. Isopleths map for runoff and sediment of simultaneous recurrence periods. 
The joint probability distribution of runoff and sediment and its change characteristics with multi-time scales

Table 3. The frequency analysis of synchronous-asynchronous encounter situation of annual rich-poor runoff and sediment (\%).

\begin{tabular}{ccccccccc}
\hline \multicolumn{3}{c}{ Synchronous frequency } & \multicolumn{1}{c}{ Asynchronous frequency } \\
\hline $\begin{array}{c}\text { Rich } \\
\text {-rich }\end{array}$ & $\begin{array}{c}\text { Normal } \\
\text { normal }\end{array}$ & $\begin{array}{c}\text { Poor } \\
\text {-poor }\end{array}$ & Total & $\begin{array}{c}\text { Rich } \\
\text { runoff-normal } \\
\text { sediment }\end{array}$ & $\begin{array}{c}\text { Rich } \\
\text { runoff-poor } \\
\text { sediment }\end{array}$ & $\begin{array}{c}\text { Normal } \\
\text { runoff-poor } \\
\text { sediment }\end{array}$ & $\begin{array}{c}\text { Normal } \\
\text { runoff-rich } \\
\text { sediment }\end{array}$ & $\begin{array}{c}\text { Poor } \\
\text { runoff-rich } \\
\text { sediment }\end{array}$ \\
\hline 24.21 & 8.04 & 24.21 & 56.46 & 8.48 & 4.81 & 8.48 & 8.48 & $\begin{array}{c}\text { Poor } \\
\text { runoff-normal } \\
\text { sediment }\end{array}$ \\
\hline
\end{tabular}

The characteristics of annual runoff and sediment with multi-time scale in its joint probability distribution space

In the long time series, the hydrologic variables change at various time scales (or periods) and the partial fluctuations. These changes and fluctuation can be decomposed by certain mathematical method.

The joint probability distribution based on copulas of runoff and sediment in the lower reaches of the Weihe River is shown in Fig. 8. Under the assumption that the evaluated criterion of standard deviation value is 0.25 , the probability series is decomposed by empirical mode decomposition method, and the border issues are addressed by the boundary extension method. The decomposed results (shown in Fig. 9-Fig. 13) include four intrinsic mode function components and one residue. We can see that: (1) The joint probability distribution of runoff and sediment can be decomposed into four oscillation components with various fluctuation periods and a trend component.

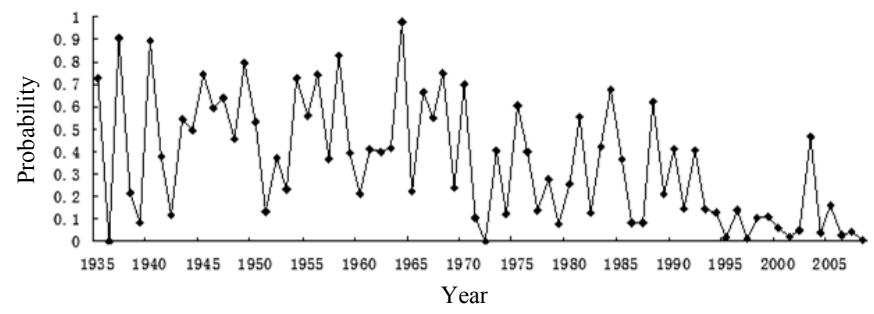

Fig. 8. The copula-based joint probability distribution of runoff and sediment.

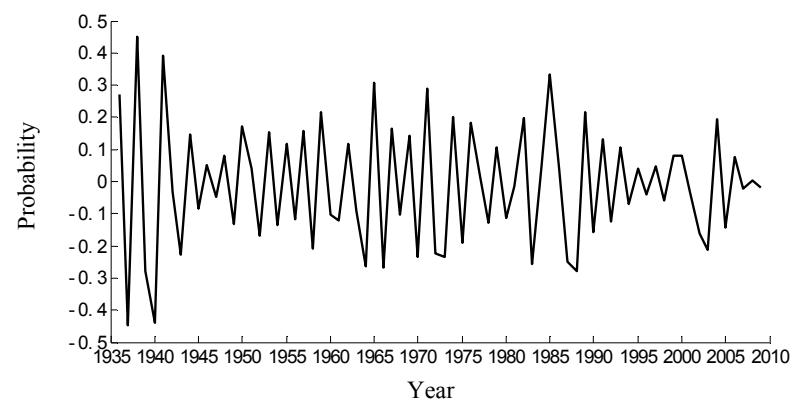

Fig. 9. The first intrinsic mode function component.

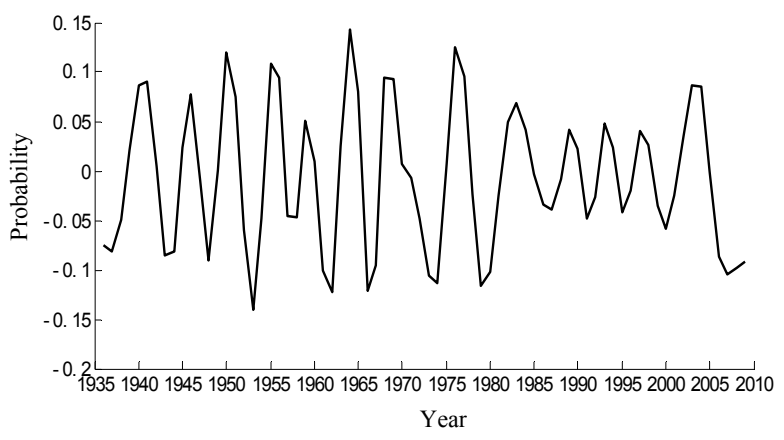

Fig. 10. The second intrinsic mode function component.

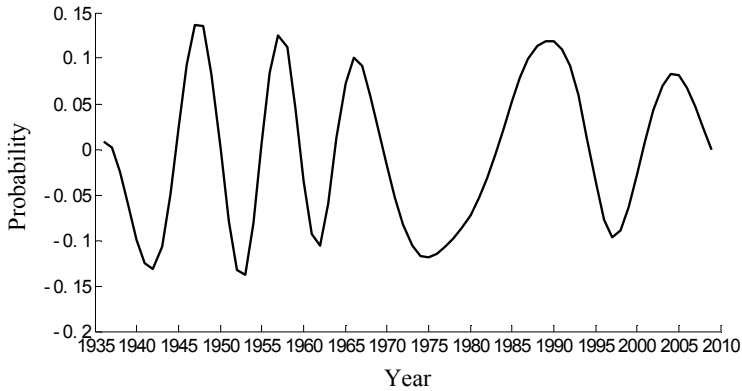

Fig. 11. The third intrinsic mode function component.

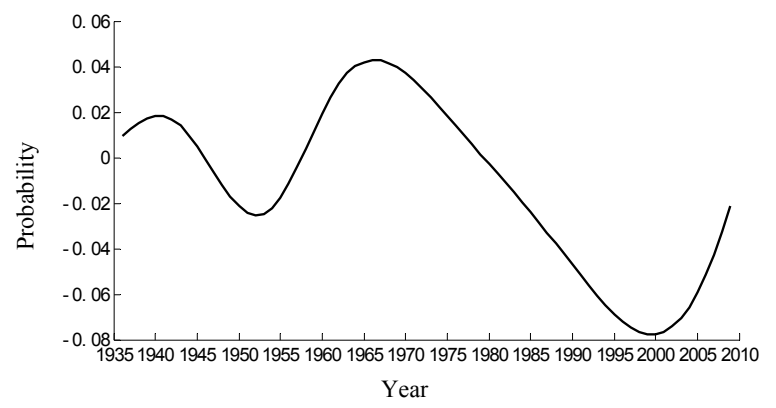

Fig. 12. The fourth intrinsic mode function component.

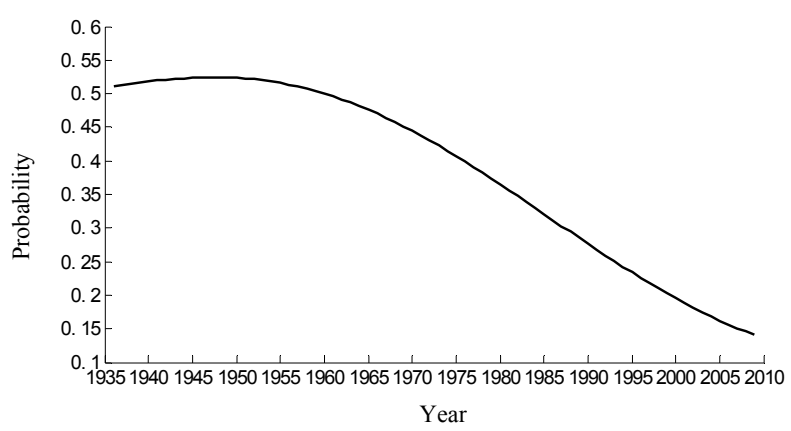

Fig. 13. The residual component.

It indicates that there has been a complex movement of runoff and sediment in the lower reaches of the Weihe River. (2)A quasi-periodic fluctuation of 2 to 4 years is presented in the first intrinsic mode function component. Larger fluctuations appeared in the 1930s, then they slowed down from the late 1950s to the early 1990s; (3) A quasi-periodic fluctuation of 4 to 8 years is exhibited in the second intrinsic mode function component. Larger fluctuations existed in early 1980 s, then they gradually slowed down and began to rise in the beginning of $21^{\text {st }}$. (4) A quasi-periodic fluctuation of 9 to 11 years is revealed in the third intrinsic mode function component. The period of 23 years started from the mid-1960s to the late 1980s, and 15 years was found in late 1980s. However, the fluctuation is not remarkable; (5) In the fourth intrinsic mode function, a quasiperiodic fluctuation of 26 years is in the whole study time scale with remarkable changes; (6) The residue component indicates 
the overall varying trend of the joint probability distribution of runoff and sediment. The peak value of 0.5244 appears in 1947 and has been decreasing since then.

\section{CONCLUSIONS}

The joint probability distribution based on the copulas can match the runoff and sediment well in the Weihe River, and the selected Frank copula function is better than others in three kinds of Archimedean copula functions. In applications with the constructed joint probability distribution, we can know the encounter frequencies of runoff and sediment in different state. The studied results show that the total frequencies of the synchronous encounter case of annual rich-poor runoff and sediment are larger than that of the asynchronous encounter case. Moreover, various recurrence periods' isopleth maps of the runoff and sediment encounter case can be obtained according to the joint probability distribution. If we have an appropriate distribution process of runoff and sediment of a typical year, we can implement the same frequency amplification method to obtain several groups of runoff and sediment with the same return period. This will provide a technical support for the planning and regulation of the Weihe River. The decomposed results by empirical mode decomposition method reveal that a sophisticated random motion exists in the lower reaches of the Weihe River, and the overall trend of joint probability distribution of runoff and sediment had increased in previous 12 years and then it was attenuated.

Acknowledgements. This research is supported by the National Natural Sciences Foundation of China (Project No. 51309202, 51379216, 50939006) and the National Key Basic Research Project of China (973-2010CB951102), and also by Program for Innovative Research Team (in Science and Technology) in University of Henan Province (No. 13IRTSTHN030).

\section{REFERENCES}

Balistrocchi, M., Bacchi, B., 2011. Modelling the statistical dependence of rainfall event variables through copula functions. Hydrol. Earth. Syst. Sci., 15, 6, 1959-1977.

Cherubini, U., Luciano, E., Vecchiato, W., 2004. Copula Methods in Finance. John Wiley, Chichester, UK.

Chowdhary, H., Escobar, L., Singh, V.P., 2011. Identification of suitable copulas for bivariate frequency analysis of flood peaks and flood volumes. Hydrol. Res., 42, 2-3, 193-216.

Compagnucci, R., Blanco, S.A., Figlioa, M.A. et a1., 2000. Variability in subtropical Andean Argentinean Atuel fiver: a wavelet approach. Environmetrics, 11, 251-269.

Correia, F.N., 1987. Multivariate partial duration series in flood risk analysis. In: Singh, V.P. (Ed.): Hydrologic Frequency Modelling. Reidel, Dordrecht, The Netherlands,pp.541 554.

Freund, J.E., 1961. A bivariate extension of the exponential distribution. J. Amer. Statist., 56, 971-977.

Ganguli, P., Reddy, M.J., 2013. Probabilistic assessment of flood risks using trivariate copulas. Theor. Appl. Climatol., $111,1-2,341-360$.

Gaucherel, C., 2002. Use of wavelet transform for temporal characterization of remote watersheds. J. Hydrol., 269, 101121.

Goel, N.K., Seth, S.M., Chandra, S., 1998. Multivariate modeling of flood flows. J. Hydraulic. Eng., 124, 146-155.
Grimaldi, S., Serinaldi, F., Napolitano, F. et al., 2005. A 3copula function application for design hyetograph analysis. IAHS Publ., 293, 203-211.

Gumbel, E.J., 1960. Bivariate exponential distributions. J. Am. Statist. Assoc., 55, 698-707.

Gumbel, E.J., Mustafi, C.K., 1967. Some analytical properties of bivariate extreme distributions. J. Am. Statist. Assoc., 62, 569-588.

Gyasi-Agyei, Y., 2012. Use of observed scaled daily storm profiles in a copula based rainfall disaggregation model. Adv. Water. Resour., 45, 26-26.

Gyasi-Agyei, Y., Melching, C.S., 2012. Modelling the dependence and internal structure of storm events for continuous rainfall. J. Hydrol., 464-465, 249-261.

Han, Y.P., Jiang, R.F., Ruan, B.Q., 2007. Analysis on Wetnessdryness encountering of runoff flow between water source region and receiving water region in the middle route of the South-to-North Water Transfer Project. Journal of North China Institute of Water Conservancy and Hydroelectric Power, 28, 8-11.

Hashino, M., 1985. Formulation of the joint return period of two hydrologic variates associated with a Poisson process. J. Hydraulic. Eng., 3, 73-84.

Huang, N.E., Shen, Z. et al., 1998. The empirical mode decomposition and the Hilbert spectrum for nonlinear and non-stationary time series analysis. Proc. Roy. Soc. London.

Huang, N.E., Shen, Z., Long, S.R. et al., 1999. A new view of nonlinear water waves: the Hilbert spectrum. Annu. Rev. Fluid. Mech., 31, 417-457.

Kao, S.C., Govindaraju, R.S., 2010. A copula-based joint deficit index for droughts. J. Hydrol., 380, 121-134.

Labat, D., Ronchail, J., Callede, J. et a1., 2004. Wavelet analysis of Amazon hydrological regime variability. Geophys. Res. Lett., 31, 33-45.

Lian, J.J., Xu, K., Ma, C., 2013. Joint impact of rainfall and tidal level on flood risk in a coastal city with a complex river network: A case study of Fuzhou City, China. Hydrol. Earth. Syst. Sci., 17, 2, 679-689.

Liu, Z.M., Chen, Z.S., 2009. Risk study of the bivariate encounter of interzone rainstorm and flood level of the outer river. Adv. Water. Resour., 20, 619-625.

Ma, M., Song, S., Ren, L., Jiang, S., Song, J., 2013. Multivariate drought characteristics using trivariate Gaussian and Student t copulas. Hydrol. Process., 27, 8, 1175-1190.

Nelsen, R.B., 1999. An Introduction to Copulas. Lecture Notes in Statistics 139. Springer, New York.

Renard, B., Lang, M., 2007. Use of a Gaussian copula for multivariate extreme value analysis: some case studies in hydrology. Adv. Water. Resour., 30, 897-912.

Salarpour, M., Yusop, Z., Yusof, F., Shahid, S., Jajarmizadeh, M., 2013. Flood frequency analysis based on t-copula for Johor River, Malaysia. J. Appl. Sci., 13, 7, 1021-1028.

Salvatore, G., Francesco, S., 2006. Asymmetric copula in multivariate flood frequency analysis, Adv. Water. Resour., 29., 1155-1167.

Singh, K., Singh, V.P., 1991. Derivation of bivariate probability density functions with exponential marginals. J. Stochastic. Hydrol., 5, 55-68.

Wang, J., Meng, J.J., 2007. Research on runoff variations based on wavelet analysis and wavelet neural network model: A case study of the Heihe River drainage basin. J. Geog. Sci., $17,327-338$.

Xiao, Y., Guo, S.L., Liu, P., 2008. Seasonal flood frequency analysis and flood prevention standard. Adv. Water. Resour., 19, 54-60. 
Xiong, L.H., Guo, S.G., Xiao, Y., 2005. Application of copulas to multivariate hydrological frequency analysis. Eng. J. Wuhan. U., 38, 16-19.

Xu, Y.P., Li, J., Cao, F.F. et al., 2008. Applications of Copula in hydrological extreme analysis. J. Zhejiang U., 42, 1119 1122.

Yan, B.W., Guo, S.G., Xiao, Y., 2007. Analysis on drought characteristics based on bivariate joint distribution. Arid. Zone. Res., 24, 537-542.

Yue, S., 2000. Joint probability distribution of annual maximum storm peaks and amounts as represented by daily rainfalls. Hydrol. Sci. J., 45, 315-326.

Yue, S., 2001. The Gumbel logistic model for representing a multivariate storm event. Adv. Water. Resour., 24, 179-85.

Yue, S., Rasmussen, P., 2002. Bivariate frequency analysis: discussion of some useful concepts in hydrological application. Hydrol. Process., 16, 2881-2898.
Yue, S., Wang, C.Y., 2004. A comparison of two bivariate extreme value distributions. Stochastic. Environ. Res. Risk. Assess., 18, 61-69.

Yue, S., Legendre, P., Bruneau, P., 1999. The Gumbel mixed model for flood frequency analysis. J. Hydrol., 226, 88-100.

Zhang, L., Singh, V.P., 2007. Bivariate rainfall frequency distributions using Archimedean copulas. J. Hydrol., 332, 93-109.

Zhou, L.Y., Zhou, S.Z., Wang, F., 2005. Multi-time scales analysis of climate variation in Leizhou peninsula during 1951 to 2003. Journal of South China Normal University, 2, $43-51$.

Received 29 April 2013 Accepted 17 March 2014

Note: Colour version of Figures can be found in the web version of this article. 